\title{
XXXIV. On the presence of titanic acid in the blood
}

\section{Mr. G.O. Rees}

To cite this article: Mr. G.O. Rees (1835) XXXIV. On the presence of titanic acid in the blood, Philosophical Magazine Series 3, 6:33, 201-202, DOI: 10.1080/14786443508648569

To link to this article: http://dx.doi.org/10.1080/14786443508648569

册 Published online: 01 Jun 2009.

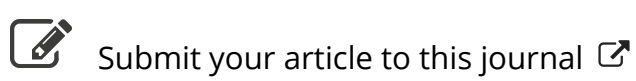

Џ Article views: 2

Q View related articles $₫$ 
Mr. G. O. Rees on the Presence of Titanium in the Blood. 201

$$
\begin{aligned}
& \text { Or, } \frac{1+r^{2^{p}}+1^{2.2^{p}}+\ldots \ldots r^{(m-1) 2^{p}}}{1+r^{2^{q}}+r^{2.2^{q}}+\ldots \ldots r^{(m-1) 2^{q}}} \\
& =\left\{1-r^{2}+r^{2 \cdot 2}-\ldots \ldots r^{(m-1) 2^{q}}\right\} \times \\
& \left\{1-r^{2}+r^{2,2}-\ldots . . r^{(m-1) 2^{q+1}}\right\} \\
& \ldots \ldots \ldots . .\left\{1-r^{2^{p-1}}+r^{2.2^{p-1}}-\ldots \ldots r^{(m-1) 2^{p-1}}\right\}
\end{aligned}
$$

to $p-q$ factors of $m$ terms each.

8. From this it appears that if an odd number of terms of a geometric series be separately raised to the power of $2^{p}$, and divided by the same terms raised to the power of $2^{q}$, the quotient will consist of $p-q$ factors, each of which is a geometric series of the same number of terms as the original one, with the signs of the even terms negative.

[To be continued.]

XXXIV. On the Presence of Titanic Acid in the Blood. By $M r$. G. O. REes.

Sir,

To Richard Phillips, Esq., F.R.S., \&c.

YOU will much oblige me by inserting the following ex-

periments in the London and Edinburgh Philosophical Magazine and Journal of Science.

Your obedient Servant,

G. O. ReEs.

While making some further observations on the presence of titanium in organic matter, I was induced to examine the blood, in order to assure myself that its existence in that fluid had not been overlooked. For that purpose the following experiments were made. A portion of incinerated blood was digested in strong nitro-muriatic acid at a boiling temperature: the solution so formed was decanted from the insoluble residue, which consisted of granular white particles in admixture with a portion of carbon that had escaped dissipation. The decanted solution was evaporated to dryness. Very dilute sulphuric acid was next boiled on the dry mass for a few minutes, when a considerable quantity of a fawn-coloured powder was observable at the bottom of the vessel: this powder was

Third Series. Vol. 6. No. 33, March 1835. $2 \mathrm{D}$ 


\section{Mr. G. O. Rees on the Presence of Titanium in the Blood.}

washed with distilled water, dried, and heated to redness in a platinum crucible; it became of a dark colour, and when cold had a distinct reddish hue, owing, doubtless, to a portion of phosphate of iron in admixture, as that substance does not redissolve with the dried chloride. The mass was therefore boiled in aqua regia, when a light coloured powder was left undissolved: this, on being examined before the blowpipe on a platinum support, gave a yellow bead (becoming colourless when cold) in the outer flame; and a yellow bead, becoming reddish while cooling, and purple inclining to blue when cold, if the inner flame was directed on it.

A second portion of incinerated blood was similarly treated, excepting that the dried chloride was (as several digestions with aqua regia were had recourse to) each time washed away from the mass in the vessel used for the digestions. By this means a residual mass was procured, of a white colour inclining to gray; this was fused with carbonate of soda, which produced a yellow colour when heated, becoming nearly white when cold. Distilled water was boiled on the fused mass, when a light flocculent white precipitate was seen floating in the liquor, and a heavier fawn-coloured powder (which gave the reactions of titanic acid before the blowpipe) appeared at the bottom of the vessel. The flocculent precipitate was collected and dissolved in cold dilute muriatic acid: the solution gave a dark green coloured precipitate when neutralized with ammonia and tested with hydrosulphuret of ammonia, and a reddish brown precipitate with infusion of galls; the sulphuret when collected and ignited behaved as titanic acid before the blowpipe. In every specimen I have examined, an insoluble residue has been observable, though strong nitromuriatic acid has been used as a solvent: this insoluble matter in every instance has been of a white or dingy white colour, becoming yellow when fused with alkaline carbonate, but not exhibiting that phænomenon when heated alone to the same extent as the titanic acid of the mineral kingdom. As I have not yet made any quantitative analysis of the incinerated blood, I cannot say that the iron exists as titanate in that substance, though titanic acid be present; but its behaviour would seem to indicate the necessity of such being the case. I have only to add, that a recent communication regarding the existence of titanic acid in Hessian crucibles can in no way interfere with any of my observations, as the whole of the crucible experiments I have detailed were conducted in platinum vessels.

Guy's Hospital, Feb. 12, 1835. 